
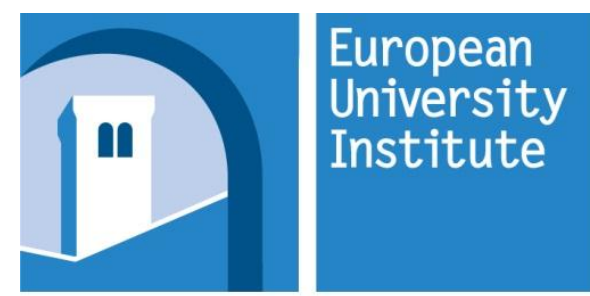

ROBERT

SCHUMAN

CENTRE FOR

ADVANCED

STUDIES

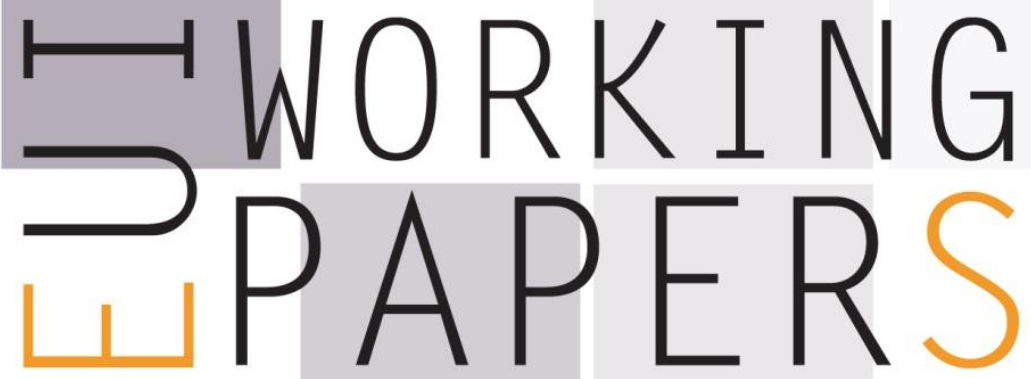

RSCAS 2014/04

Robert Schuman Centre for Advanced Studies Climate Policy Research Unit

The EU ETS: Eight Years and Counting

Denny Ellerman, Claudio Marcantonini and Aleksandar Zaklan 

European University Institute

Robert Schuman Centre for Advanced Studies

Climate Policy Research Unit

\section{The EU ETS: Eight Years and Counting}

Denny Ellerman, Claudio Marcantonini and Aleksandar Zaklan

EUI Working Paper RSCAS 2014/04 
This text may be downloaded only for personal research purposes. Additional reproduction for other purposes, whether in hard copies or electronically, requires the consent of the author(s), editor(s). If cited or quoted, reference should be made to the full name of the author(s), editor(s), the title, the working paper, or other series, the year and the publisher.

ISSN 1028-3625

(C) Denny Ellerman, Claudio Marcantonini and Aleksandar Zaklan, 2014

Printed in Italy, January 2014

European University Institute

Badia Fiesolana

I - 50014 San Domenico di Fiesole (FI)

Italy

www.eui.eu/RSCAS/Publications/

www.eui.eu

cadmus.eui.eu 


\section{Robert Schuman Centre for Advanced Studies}

The Robert Schuman Centre for Advanced Studies (RSCAS), created in 1992 and directed by Brigid Laffan since September 2013, aims to develop inter-disciplinary and comparative research and to promote work on the major issues facing the process of integration and European society.

The Centre is home to a large post-doctoral programme and hosts major research programmes and projects, and a range of working groups and ad hoc initiatives. The research agenda is organised around a set of core themes and is continuously evolving, reflecting the changing agenda of European integration and the expanding membership of the European Union.

Details of the research of the Centre can be found on:

http://www.eui.eu/RSCAS/Research/

Research publications take the form of Working Papers, Policy Papers, Distinguished Lectures and books. Most of these are also available on the RSCAS website:

http://www.eui.eu/RSCAS/Publications/

The EUI and the RSCAS are not responsible for the opinion expressed by the author(s).

\section{Climate Policy Research Unit}

The Climate Policy Research Unit (CPRU) is a research group within the Robert Schuman Centre for Advanced Studies under the LLoyola de Palacio Chair. The goal of the CPRU is to provide a reliable source for information and analysis of EU climate policy and a forum for discussion of research carried out in this area among government officials, academics and industry.

The CPRU was established in 2010 at the initiative of Josep Borrell, former President of the EUI and former President of the European Parliament, as a means of providing more focus to European climate policy developments. The director of the CPRU is Denny Ellerman, part-time professor at the RSCAS, and recently retired as a Senior Lecturer from MIT's Sloan School of Management. The CPRU works in collaboration with the energy and regulatory policy research groups of the Florence School of Regulation and Loyola de Palacio Chair and with the Global Governance Programme at the EUI. Starting in 2012, the CPRU has been funded primarily by the European Commission (DG Climate Action).

The opinions expressed in this paper are those of the author(s) and do not represent the views of the European University Institute or any of its subsidiary components or those of the European Commission.

For more information:

http://fsr.eui.eu/CPRU/Index.aspx 



\begin{abstract}
This paper provides an introduction to the EU's Emissions Trading System. As such it provides a discussion of the historical and legal context in which the EU ETS developed and now operates, a presentation of the key performance indicators for the first eight years through the end of the second phase in 2012, and some concluding observations on the system's future. The paper is purposively descriptive to provide background for more analytically oriented articles, as well as to provide a matter-of-fact presentation for readers who wish to learn about or be updated on the progress of the EU ETS.
\end{abstract}

\title{
Keywords
}

European Climate Policy, EU ETS, Carbon Price. 



\section{Introduction}

The European Union's Emissions Trading System (EU ETS) is arguably the most important marketbased application of economic principles in the climate domain and the largest cap-and-trade program yet implemented. In 2013, it entered its ninth year of existence, having completed the second phase (2008-12) and begun its third phase (2013-2020). During these eight years the EU ETS has seen a number of significant changes based on a succession of landmark legislative achievements. It has evolved from a system with 25 national caps and decentralized allocation based on national allocation plans and dealing with $\mathrm{CO}_{2}$ emissions alone towards a centralized system including several greenhouse gases (GHGs) and featuring an EU-wide cap indefinitely declining at an annual rate of $1.74 \%$. Having entered Phase III a predominance of free allocation has given way to a combination of auctioning and free allocation based on benchmarking for sectors deemed at risk of carbon leakage, with full auctioning for all sectors as the medium-term goal. Over the course of its relatively short history, the system has been expanded in scope to include both additional countries and new sectors. Furthermore, links have been established with both the permit trade under the mechanisms of the Kyoto Protocol (KP) and non-EU national emission trading systems.

From its inception in 2005, the EU ETS has been the subject of a vigorous debate both in policy circles and among the wider public. It has also been the subject of considerable academic research. Various aspects of the EU ETS have been debated at various times, including allocation rules, the appropriate level of permit prices and its place in the wider context of European climate policy, particularly given a number of national policies and related EU-level policy targets.

The objective of this paper is to provide a descriptive analysis of several aspects of the EU ETS from its inception through 2012, including both its achievements and challenges it has encountered. We also evaluate in some detail its performance so far by focusing on a number of key areas, including emissions, the development of permit prices, as well as offset use and prices. We also summarize particularly salient aspects of the current short and medium-term policy debate. The remainder of the paper is structured as follows: Section II describes the historical development of the EU ETS and its relations with the other EU and international climate polices; Section III presents our analysis of the performance of the system with regard to $\mathrm{CO}_{2}$ abetment, carbon price and the use of offsets; Section IV summarizes the current debate about its future development. Section V concludes.

\section{History and Structure}

The EU ETS is a classic cap-and-trade system that as of 2013 includes some 13,500 stationary installations in the electric utility and major industrial sectors and some 2000 airline accounts in the now twenty-eight member states of the European Union (EU) plus three members of the closely associated European Economic Area (EEA): Norway, Iceland, and Liechtenstein. Approximately two billion tons of carbon dioxide $\left(\mathrm{CO}_{2}\right)$ and some other greenhouse gases (GHGs) are included in the system, about $4 \%$ of global GHG emissions. Aside from its size, an important distinguishing characteristic of the EU ETS is that it is implemented in the multinational framework that is the European Union and not the canonical unitary state of most theory and all past practice with cap-andtrade systems.

\section{a. Legislative development}

The first serious indication that the European Union might implement an emissions trading system came in 2000 when the Green Paper on greenhouse gas emissions trading within the European Union was issued (European Commission, 2000). This paper raised the issue explicitly but delicately of whether the European Union should implement an EU-wide cap-and-trade system to limit greenhouse gas (initially $\mathrm{CO}_{2}$ ) emissions as a complement to other policies and measures, implemented mostly at 
member-state level. It was also proposed as a means to ensure achievement of the targets to which the EU and its member states had committed in the yet-to-be-ratified Kyoto Protocol. The essential features of the future system were laid out in this document, essentially, a trial period to run from 2005 through 2007 to prepare for full implementation for a five-year period 2008-2012 corresponding to the First Commitment Period of the Kyoto Protocol. As is the usual practice with Green Papers in the EU, comment was solicited, and following review of those comments, a legislative proposal to establish such a system was forwarded to the European Parliament in late 2001. Two years later following extensive debate, the Emissions Trading Scheme (ETS) Directive was unanimously adopted by the European Council of Member States in October 2003 (OJEU, 2003). This directive was quickly followed by an amendment, known as the Linking Directive (OJEU, 2004), which allowed credits from the Kyoto Protocol's Clean Development Mechanism (CDM) and Joint Implementation (JI) to be used for compliance on an equal status with European Union Allowances (EUAs). Use of these credits for compliance was subject to a negative list banning certain types of projects (large hydro, nuclear) and a yet-to-be-defined limit on the number of credits allowed, which conceptually was to be approximately $50 \%$ of the expected required reduction of $\mathrm{CO}_{2}$ emissions. ${ }^{1}$ As initially proposed in the Green Paper, the system went into effect with the year 2005, fifteen months after adoption of the ETS Directive.

In keeping with the spirit of the trial period, the ETS Directive called for the Commission to conduct a review of the ETS experience in the first years and to propose appropriate changes. This review began in 2006 and eventuated in the agreement on the adoption of significantly revised Amended Directive in late 2008 that would govern the system from 2013 on (OJEU, 2009). The most important changes were:

- Adoption of an indefinitely declining EU-wide cap;

- Adoption of auctioning as the basic allocation principle to be applied completely for the electric utility sector in 2013 and to be phased in by 2027 for the remaining industrial sectors;

- Residual free allocation during the transition period for industrial facilities according to centrally determined benchmarks;

- Inclusion of the chemical and aluminum industries; and

- Changes in offset provisions that further limited the type and quality of allowed credits, greatly reduced the allowed use of project credits, and set limits on offset use through 2020, while expanding the scope for linking with other cap-and-trade systems.

\section{b. From an initial, highly decentralized structure to a common $E U$-wide cap}

The most important change in the Amended Directive was the adoption of an EU-wide cap that would decline indefinitely at a rate of $1.74 \%$ annually. The significance of this change can only be appreciated by recalling the considerable decentralization of cap-setting and allocation as provided in the initial ETS Directive and as implemented in the first and second trading periods. The EU ETS was then best understood as a system for linking 25 individual systems that set their own caps and determined their own allocations subject to some mutually agreed review by the European Commission. Each member state developed a National Allocation Plan (NAP) in which was specified the total number of EUAs to be created and how they would be allocated to affected installations in that member state. These plans were subject to review by the Commission but were considered final unless, in an unusual twist of EU procedures, the Commission rejected the NAP for non-compliance with certain criteria specified in the ETS Directive. In effect, the EU-wide cap was the sum of the

\footnotetext{
This limit of offset use was subsequently determined by the National Allocation Plans submitted for the second phase of the EU ETS. The individual member-state limits summed to approximately 1.3 billion allowable credits over the 2008-12 trading period.
} 
constituent member-state "caps" and would not be known definitively until the last NAP was accepted (not rejected).

The NAP process proved to be a long, laborious, and unrewarding procedure for all concerned. In both cycles of NAP development and review, for the 2005-07 and 2008-12 periods, the Commission rejected many NAP submissions and several member states subsequently challenged these rulings before the European Court of First Instance. Setting aside the legal challenges, the last NAP for the first, trial period was accepted in June 2006, eighteen months after its start. The second NAP cycle started earlier, some eighteen months before the start of 2008, but member states were often late in submitting and the final NAP acceptance did not occur until December 2007, one month before the start of the second phase. A year later, the member states meeting in Council agreed, again unanimously, to abandon this cumbersome process and to adopt a system-wide cap with a new set of principles for allocation that would take effect in 2013. While a third phase was specified lasting eight years, it was also agreed that the cap would decline at a rate of $1.74 \%$ annually, calculating from 2010 and taking the second period cap as the starting point, and continue indefinitely through subsequent eight-year trading periods, unless subsequently changed by further amendments to the ETS Directive.

\section{c. Auctioning and centralized allocation rules}

The adoption of a common system-wide cap was closely related to parallel changes in the procedures for allocating allowances. The two greatest critiques brought against the NAP process in the first phase were "windfall profits" from free allocation and the competitive impact of different allocations to like facilities in various member states in what is intended to be a single market. Both of these critiques were substantively deficient and legally uninformed, but they were politically potent. ${ }^{2}$ Decentralized free allocation had been politically necessary initially to ensure the participation of all member states in this essentially multi-national trading system. Despite strong sentiment in favor of significant auctioning from the beginning by the European Parliament, the directive agreed in 2003 required that at least $95 \%$ of allowances be allocated freely in the first phase and $90 \%$ in the second phase. The wonder is not so much that free allocation prevailed initially, but that it was abandoned so quickly.

Establishing auctioning as the fundamental principle for allocation with a phase-in from 2013 to 2027 answered both the critiques of the NAP process, windfall profits and lack of harmonization, in one fell swoop. All installations would eventually pay for their allowances and a zero free allocation is "harmonized" by definition. However, implementation of universal auctioning would not be so sudden and the transitional free allocation would be harmonized at the EU level.

The phase-in of auctioning differs according to industrial sector, exposure to extra-EU competitive impact, and EU accession. The electric utility sector, which constitutes about 50\% of EU ETS emissions (Trotignon and Delbosc, 2008, p. 23), was deemed not to face any competitive threat and consequently free allocation is brought to an abrupt halt at the end of the second phase (2012) with some derogations for particularly coal-dependent new member states. These exceptions would have until 2020 to phase out free allocation provided that investments in the modernization of the electricity sector are made. The number of allowances to be distributed and the investment in modernization would be specified in NAP-like plans submitted by those member states and subject to Commission review.

The non-electric, industrial sectors, which are exposed to varying degrees to extra-EU competitive pressures, will experience a more gradual phase out of free allocation, which, furthermore, will be

Although never well defined, windfall profits tended to focus on the increased prices in the electricity sector despite utilities not having to pay for most if not all of their allowances. Similarly, it is not obvious that differing lump-sum free allocations had any effect on the competitive position of firms within the EU. Most of the observed differences reflected differing sizes and production processes. For a fascinating and in-depth analysis of the debate on the EU ETS, see chapter five of Skjaerseth and Wettestad (2008). 
according to EU-wide sector benchmarks that were to be developed prior to 2013. Allocation would start at $80 \%$ of the full benchmark in 2013 and be reduced to $30 \%$ by 2020 and then completely phased out by 2027. Certain sectors may be determined to be threatened competitively and consequently continue to receive free allocations at the full benchmark level. ${ }^{3}$

Perhaps no concept was more advocated during the NAP processes for the first and second trading periods, and less practiced, than benchmarking (Ellerman, Buchner and Carraro, 2007). Despite many proposals, some self-serving, the basic problem was the lack of agreement on a suitable benchmark for $\mathrm{CO}_{2}$ emissions. As a result and also because of the rushed conditions under which the NAPs were developed, the inevitable basis for allocation was historical emissions over some pre-2005 period. This lack of agreement at the implementing level was resolved in the Amended Directive by the requirement that EU-wide benchmarks be the average emission rate of the $10 \%$ most carbon-efficient installations for each sector in 2005. The remaining problem, to define sectors, was not easy, but with the conceptual standard agreed and several years for the Commission and industry to work out the data problems, benchmarks were established for some 50 sectors more than a year before the end of Phase II. Member states subsequently submitted National Implementation Measures indicating installations eligible for free allocation, their sectors, and proposed allocations according to these benchmarks. These residual free allocations are subject to the same annual $1.74 \%$ decrement that now governs the whole system, as well as a ratchet of about $6 \%$ to reconcile the sum of these free allocations with the previously decided cap, auction amounts, and new entrant reserves (OJEU, 2013b).

No discussion of allocation would be complete without consideration of the use of the revenues from auctioning. The long-standing fiscal rule in the European Union made this issue fairly easy: Brussels is to have no independent sources of revenue other than as provided by the member states through the seven-year budgets. Moreover, the Commission cannot tell member states how to spend the revenue raised by each. Thus, revenues from the allowance auctions will be distributed to member states according to the "auction rights" established by formula in the Amended Directive. ${ }^{4}$ These new rights are distributed in a manner inversely but loosely related to per capita income. The member states with the highest per capita income would receive auction rights in 2020 that would be between $30 \%$ and $32 \%$ less than their 2005 verified emissions (compared to the EU-wide cap that is $21 \%$ lower), while member states with lower per capita income, generally new member states in Eastern Europe, receive auction rights greater than their 2005 emissions, including Latvia with an auction share $67 \%$ greater. Finally, although the Commission's original proposal for the Amended Directive would have required $20 \%$ of auction revenues to be spent for climate-related purposes; the final language increased the ambition but softened the commitment by stating agreement to make best efforts to dedicate up to $50 \%$ of auction revenues for these purposes.

When all is taken into account, the amount of auctioning increased significantly in 2013 and will continue to increase until in 2027 all permits are auctioned except for installations in sectors then determined specifically to be threatened competitively. In the interim, the remaining, transitional free allocation to industrial facilities is harmonized to EU-wide benchmarks. This is a remarkable evolution within less than ten years from a system in which largely sovereign nations demanded and received considerable deference in cap-setting and allocation to one in which those decisions were made centrally without member-state distinctions other than in the receipt of the revenues from the increasing share of the cap that would be auctioned.

3 Nearly all industrial sectors were determined to be competitively threatened for the first two years of Phase III; however, this administrative determination is valid for only a limited time and the current redetermination is expected to result in many fewer sector exemptions due to the currently low EUA prices.

4 The actual auctioning may occur through a central platform established by the Commission or individually by the member state. Three member states, Germany, the UK, and Poland, have chosen to establish their own auction platforms. All other member states have opted to auction their rights through the common platform. For these member states, the revenue produced by auctioning their shares are returned to the member states less the proportionate share of auctioning expenses. 


\section{d. The relationship to the Kyoto Protocol and other trading systems}

The EU ETS would likely not exist were it not for the Kyoto Protocol (KP); yet, implementation of the EU ETS is independent of the KP. The system adopted in 2003 was proposed and justified as a means for the EU and its member states to meet their Kyoto obligations, as seen in the structure of the system - a preparatory "trial" period followed by a "real" trading period corresponding to the First Commitment Period of the Kyoto Protocol. Nevertheless, implementation was not made contingent on the entry into force of the KP, despite the considerable uncertainty surrounding that circumstance when the initial ETS Directive was adopted. Moreover, the continuation of the EU ETS to 2020 and beyond, as specified in the amendments agreed in late 2008, is also independent of international agreement. The only part of the Amended Directive that is contingent on international agreement is the commitment made in preparation for the Conference of the Parties to the UNFCCC held in Copenhagen in late 2009 that the EU would reduce its emissions to 30\% below 1990 levels if there were an adequate international agreement. The commitment to a $20 \%$ reduction below 1990 levels by 2020 (and to even lower levels thereafter) is unilateral, firmly embedded in EU law, and not dependent on international action.

A similar evolution from close attention to international agreements, up to now the Kyoto Protocol, to a more independent stance can be observed in the provisions concerning linkage, a generic term that embraces two related concepts: the acceptance of international credits from the Kyoto Protocol's Clean Development Mechanism (CDM) and Joint Implementation Procedures (JI), and mutual recognition with other cap-and-trade systems. The initial dependence on international agreement is explicit in the Linking Directive's effective delegation of certifying authority to the KP's CDM and JI crediting mechanisms. Still, the EU retained its prerogative, as buyer, to limit the use of KP certifying credits, as evidenced by the Linking Directive's limit on credit use and its prohibition of offsets from certain types of projects. That independence was reinforced in the Amended Directive and subsequent regulatory actions.

The Amended Directive embraced what could be seen as a "graduation" policy in that international credits based on projects that would be severely restricted in favor of those originating from something that would look more like a cap-and-trade system with an absolute cap but which might embrace only a sector and be sub-national. An overall limit of 1.6 billion international credits for the combined first and second periods, 2008-20, was established. This new limit effectively authorized banking of credit use from the second to the third period and an additional 0.3 billion credits in the third period. However, credit use after 2012 was restricted to credits from existing projects registered before the end of 2012 and from new projects only in the "least-developed" nations, meaning other than China, India, Brazil, etc. In addition, the Commission moved unilaterally in 2010 to announce that CDM credits generated by high global warming potential industrial gas projects would not be accepted for compliance beyond 2012 under any circumstances (OJEU, 2011).

While most of the discussion with respect to linking has been focused on project credits to date, attention is now turning to mutual recognition. The initial 2003 Directive restricted mutual recognition to parties to the KP, implicitly national systems. The Amended Directive drops all mention of the KP and explicitly mentions potential linkage to sub-national systems so long as they have an absolute cap. Furthermore, the right of the EU to establish bilateral agreements independent of any international agreement is asserted. Two instances of prospective mutual recognition exist, one announced (Australia) and the other under negotiation (Switzerland). Similar linkages are being considered with the proposed South Korean system and the pilot or national systems in China as these are implemented. While all of these countries are participants in international climate agreements, the distinguishing characteristic of these agreed and contemplated linkages by mutual recognition is that they are bilateral, negotiated between the parties directly and not part of some larger international agreement like the KP. 
While the announced link with Australia has been called into question by the recent election in that country, it offers an interesting example of how bilateral mutual recognition can be accomplished in phases. The Australian cap-and-trade system began in mid-2012 with the government establishing a fixed price (by a standing offer to buy and sell allowances) for three years, after which the ceiling and floor price bounds would be widened to allow the emergence of a regular allowance market. The agreement to link with the EU ETS eliminated the floor price as of 2015 and in its stead allowed owners of affected Australian installations to acquire and surrender EUAs, thereby effectively making the EUA price the effective Australian floor price, at least as long as EUA prices are lower than the Australian price. Complete linking and full mutual recognition would not occur until 2018 when owners of EU ETS installations could surrender Australian allowances for compliance.

Finally, it should be noted that Norway, Iceland, and Liechtenstein became part of the EU ETS in 2008 as a result of negotiations between the EU and these three members of the European Economic Area. Norway had already established a GHG emissions trading system in 2005 and it was merged into the EU ETS as were the few installations in the other nations. While not members of the EU, these three nations of the European Economic Area have close ties to the member states of the European Union and often voluntarily transpose EU Directives into their own legislation as a means of fostering exchange with EU member states.

\section{e. Relation to other climate and energy policies}

Although heralded as the main instrument of the EU's climate policy, the EU ETS is not the only instrument. The EU's climate policy is famously dubbed $20-20-20$ by 2020 . This slogan refers to three targets to be achieved by 2020: a 20\% reduction of GHG emissions from 1990 levels, a $20 \%$ share of total energy consumption from renewable energy, and a $20 \%$ improvement in energy efficiency. While the 20-20-20 headline suggests equal status for achieving the three goals, their legal status varies. The GHG emissions reduction and renewable energy share targets are binding while the energy efficiency target is indicative. ${ }^{5}$

From the standpoint of the EU ETS, the measures adopted by member states to achieve the renewable energy and energy efficiency targets do have effects on the $40 \%$ of EU GHG emissions that are included in the EU ETS. In particular, several member states have provided strong incentives to develop wind and solar energy capacity within the electricity sector. In these member states, most notably Germany and Spain, the generation of electricity from wind turbines has been significant and had a demonstrable effect on the generation of electricity from $\mathrm{CO}_{2}$ emitting, fossil fuel generating plants. What remains to be seen is whether the effects of this reduction in demand and in the price of allowances are large or small.

EU-level climate policy is not the only source of potential overlap with the EU ETS. Member states can adopt energy or climate policies on their own that will also have an independent effect on ETS emissions in that member state and therefore on the ETS-wide price and distribution of abatement. Two salient, current examples with opposite effects are the German phase-out of nuclear power and the UK's carbon price floor. Following the Fukushima accident in March 2011, the German government accelerated its policy to phase-out nuclear power by shutting down eight reactors immediately and directing the others to close down by 2022 . While one can debate how much zeroemission renewable energy can substitute for nuclear generation during the phase-out, there will likely be some increased reliance on fossil generation, both natural gas and coal-fired, and consequently an increase in demand for allowances and in the resulting price, implying more abatement from other sources in the ETS including notably outside Germany.

5 Binding in the EU context means that the Commission can bring member states before the European Court of Justice for failure to comply with agreed Directives. 
The opposite effect can be anticipated from the UK carbon price floor. Starting in April 2013 and in order to encourage investment in low-carbon generating capacity, the UK is imposing a supplementary tax rate, called a carbon price support, on fossil fuel supplies to electricity generating facilities, calculated to yield a carbon price of £16/tonne-CO2 in 2013 and £30/tonne-CO2 in 2020 (approximately $€ 19 /$ tonne and $€ 35 /$ tonne) after taking the EUA price into account. With a current EUA price of around $€ 5 /$ tonne, this measure imposes a significantly higher carbon price on the UK electricity sector with consequent effects on the current dispatch of existing capacity and the consequent demand for allowances and their price. As is the case with the overlapping EU-level renewable energy and energy efficiency mandates, the direction of the opposing effects of the German nuclear phase-out and the UK carbon price floor on the EUA price is clear but the magnitudes are not.

\section{f. The Inclusion of aviation emissions}

In December 2006, the Commission proposed, and in November 2008, the Council adopted, a Directive to include aviation emissions within the EU ETS (OJEU, 2009). Beginning in 2012, the Directive applies to $\mathrm{CO}_{2}$ emissions for all flights within and between EU member states (and the three EEA members of the EU ETS), as well as to emissions emitted during the entirety of all international flights taking off or landing in airports of countries participating in the EU ETS, regardless of the points of origin or destination for those flights. Although constituting only three percent of EU ETS emissions, these emissions are among the fastest growing sources of GHG emissions and, unlike other transportation emissions, jet fuel is exempt from the taxes applicable to most other petroleum products in Europe. Finally, the Directive was adopted following the earlier failure of the International Civil Aviation Organization (ICAO) to take any measures to limit GHG emissions from aviation.

The aviation sector is not completely integrated with the ETS in that trading between the aviation sector and the rest of the ETS is one-way: EUAs can be used for compliance by airline operators, but the separate allowances distributed against the aviation sector cap, European Union Aviation Allowances (EUAAs) cannot be used for compliance in the rest of the EU ETS. Otherwise, provisions are similar to those in the ETS. The aviation cap is set at $97 \%$ of historical baseline emissions (the annual average of 2004-06) in 2012 and 95\% thereafter. 15\% of these allowances are to be distributed by auctioning, $3 \%$ are set aside in a reserve for new entrants, and the rest are distributed by free allocation in proportion to each operator's share of the historical baseline.

As 2012 approached and began, the inclusion of aviation emissions for international flights (about $2 / 3^{\text {rd }}$ of the total) became increasingly controversial with non-EU airlines, particularly those from the US, China, Russia and India. In 2010, the Air Transport Association of America challenged the validity of the Directive before the UK's High Court of Justice, which ruled against the plaintiffs in December 2011. Continuing controversy, the threat of trade reprisals, and arguments that ICAO would develop more appropriate measures led the Commission to propose and the Parliament and Council to decide to exempt international flights from compliance requirements for 2012 pending proposed action by the ICAO General Assembly in the fall of 2013 (OJEU, 2013a), while continuing to include aviation emissions for all intra-EU flights. The ICAO General Assembly agreed to develop a global trading system for aviation emissions to take effect in 2020. In response, the EU is in the process of amending the Aviation Directive to include emissions only over EU airspace from flights originating from or destined to locations outside the EU. 


\section{Performance}

\section{a. Emissions}

The first and most important measure of performance for any cap-and-trade system is emissions: are they being reduced? A reduction implies some reference point which could be a particular year or some counterfactual. The most straight-forward reference point is some earlier year since counterfactuals are always hypothetical; however, such comparisons also suffer from not accounting for other non-policy related factors that may have affected emissions. The most frequently mentioned of these other factors for $\mathrm{CO}_{2}$ emissions is the level of economic output and it is possible to compare the measures of economic output with emissions normalized in some year. Figure 1 does this for EU ETS emissions, real Gross Domestic Product (GDP) for the twenty-five EU member states initially part of the EU ETS (EU25) and of the industrial component of real GDP, which includes electricity generation, and most closely approximates the underlying economic activity of the sectors included in the EU ETS. All three indices are normalized to the year 2004, the year preceding the start of the EU ETS.

Figure 1: EU 25 GDP, Industrial Output (GVA) and $\mathrm{CO}_{2}$ Emissions

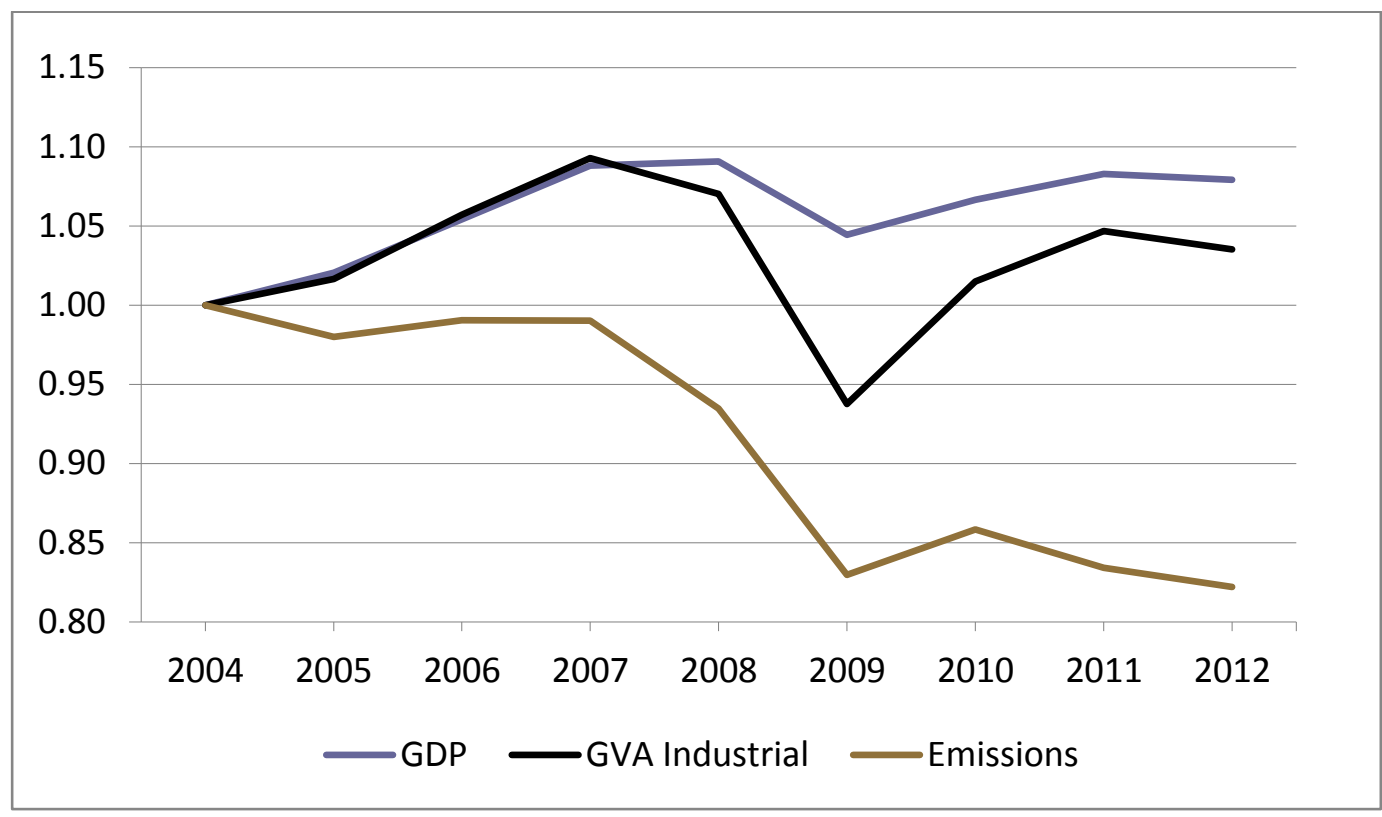

Source: Elaborated from Eurostat and CITL/EUTL data-base.

The financial crisis of 2008 and the ensuing Great Recession had a noticeable effect on GDP and especially on industrial output and $\mathrm{CO}_{2}$ emissions. However, since the low point in 2009, GDP and industrial production have rebounded to within $1 \%$ of the 2007 peak in the case of GDP and to within $5 \%$ for industrial production, as of 2012. $\mathrm{CO}_{2}$ emissions have followed a different path: a $3.4 \%$ rebound occurred in 2010 (to be compared with a $6.6 \%$ rebound in industrial output), but that was it. Since then $\mathrm{CO}_{2}$ emissions have continued to decline and were in 2012 at a lower level than in 2009. Over the entire eight-year period, GDP has risen at an average annual rate of $0.95 \%$ and industrial output at an average annual rate of $0.38 \%$, while $\mathrm{CO}_{2}$ emissions have been reduced by an average annual rate of $2.4 \%$. The ratio of emissions to GDP has declined at an average rate of about $3.3 \%$, which can be compared with a rate of decline of about $1 \%$ in the five years leading up to 2004.

Two clarifications need to be made about Figure 1. First, the line for emissions is that for emissions from the initial EU25 without taking account of changes in the perimeter of the EU ETS since 2005. 
Figure 2 compares total ETS emissions taking account of all perimeter changes with those shown in Figure 1 and several other intermediate definitions.

Figure 2: EU ETS Emissions by Perimeter

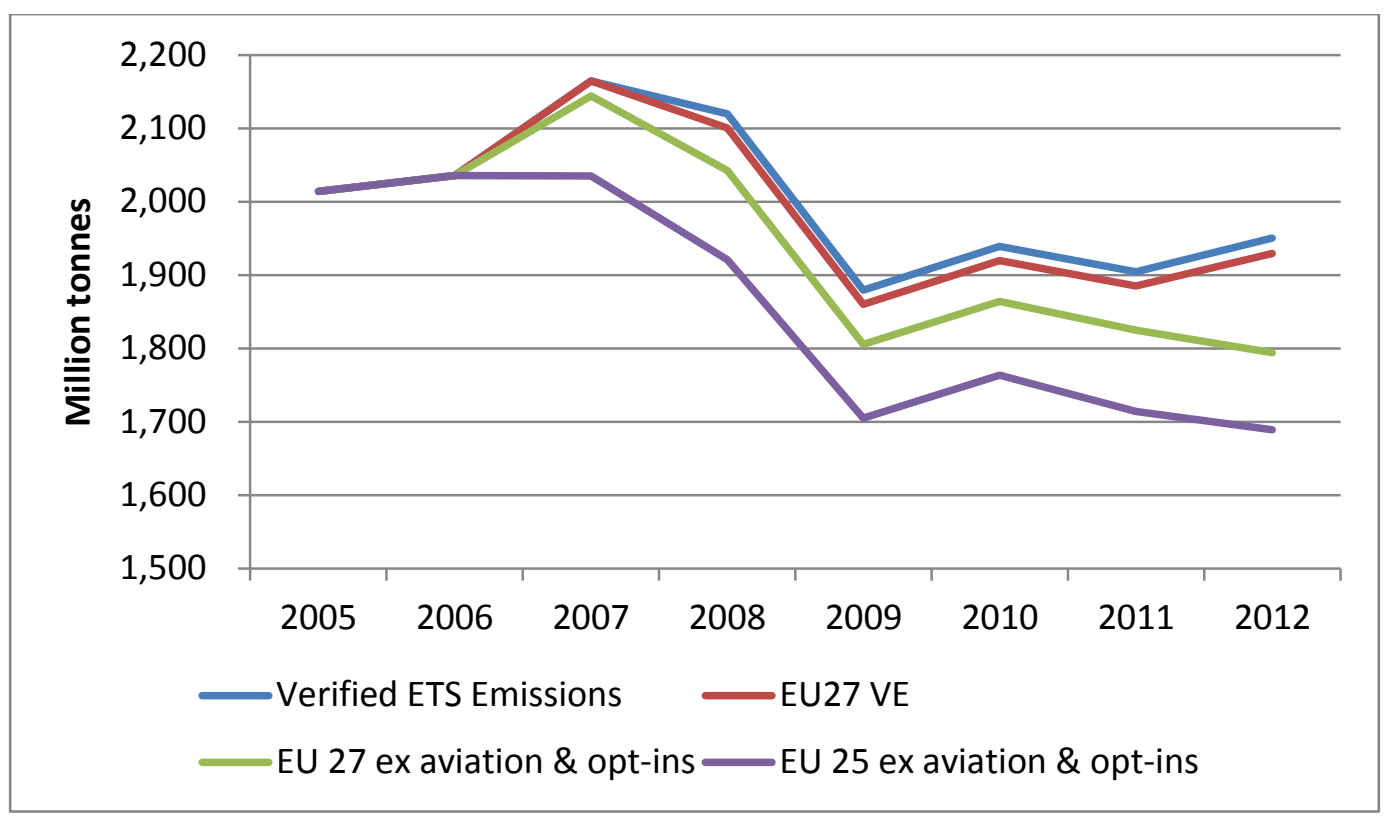

Source: Elaborated from CITL/EUTL data-base

There have been three major changes of perimeter since the start of the system. In 2007, Romania and Bulgaria become members of the European Union thereby creating the EU27 (now 28 with the addition of Croatia in July 2013) and expanding the perimeter by 109 million tons of $\mathrm{CO}_{2}$ emissions (about 5\%). Then in 2008, the perimeter was increased by the addition of Norway, Iceland, and Liechtenstein to the system (20 million tons) and more installations, some emitting nitrous oxides, were added within the existing EU27 (55 million tons). Finally, in $2012 \mathrm{CO}_{2}$ emissions from aviation within the EU were included, adding another 80 million tons. In all, the perimeter has been expanded by about 13\%. With the start of Phase III in 2013, two more sectors were brought within the perimeter, chemicals and aluminum, including in the latter case another GHG, perfluorocarbons.

The second clarification to be made concerning these two figures is that other policy measures, as well as the long-term secular trend to increasing energy efficiency, have contributed to the reduction of $\mathrm{CO}_{2}$ emissions within the EU ETS. Sorting out these effects is not easy, still, even generous estimates for the effect of overlapping policies and autonomous improvements in energy efficiency seem unlikely to be able to account for the $17.5 \%$ reduction in same-perimeter, EU25 emissions since 2004.

The respectable story about the effect of the EU ETS on $\mathrm{CO}_{2}$ emissions within affected sectors has been obscured by the controversies about "over-allocation." This ill-defined and over-used term ignores both banking when allowed and the difficulty of cap-setting under uncertainty. The EUA price in the first period (when banking was not allowed) did fall to zero as the end of the period approached, but the degree of "over-allocation," as measured by the surplus of allowances issued to verified emissions was small: 83 million allowances or $1.3 \%$ of total emissions of 6.18 billion in the three years of Phase I. Given the difficulties of setting a cap at or slightly below expected business-as-usual (BAU) emissions even with good emissions data, not to mention the poor data and the compressed time schedule faced in the first period (cf: Ellerman, Buchner, and Carraro, 2007), the difference is small. In addition, there was some abatement in the first twenty months or so of the program when a significant price prevailed. While emissions may have risen back to BAU levels in 2007, the earlier abatement could not be taken back and would show up as surplus in a period with no banking. 
Banking was allowed in the second period, as well as the use of offsets, and the excess of allocation plus offset use over verified emissions is much larger. Excluding aviation allowances, a total of 10.0 billion allowances were allocated to installations over the five years of Phase II, another 0.5 billion allowances have been auctioned (including unissued new entrant reserves). Verified emissions during Phase II were 9.7 billion tons and 1.1 billion offsets were used for compliance, so that the call on EUAs was 8.6 billion of the 10.5 billion issued. The resulting bank of 1.8 billion is about $17 \%$ of the Phase II emissions. This is a large bank and the source of much controversy as Phase III begins. Despite the large bank, the price of allowances is still positive (around $€ 5$ as of the summer of 2013) and is a strong indicator that future scarcity is expected with the currently embedded cap, declining indefinitely at $1.74 \%$ annually.

Figure 3 provides a long term perspective on ETS sector emissions and the cap with and without emissions from 1990 through 2050 assuming no further change in the cap or allowed offset use.

Figure 3: ETS Sector Emissions and Cap in Long-term Perspective

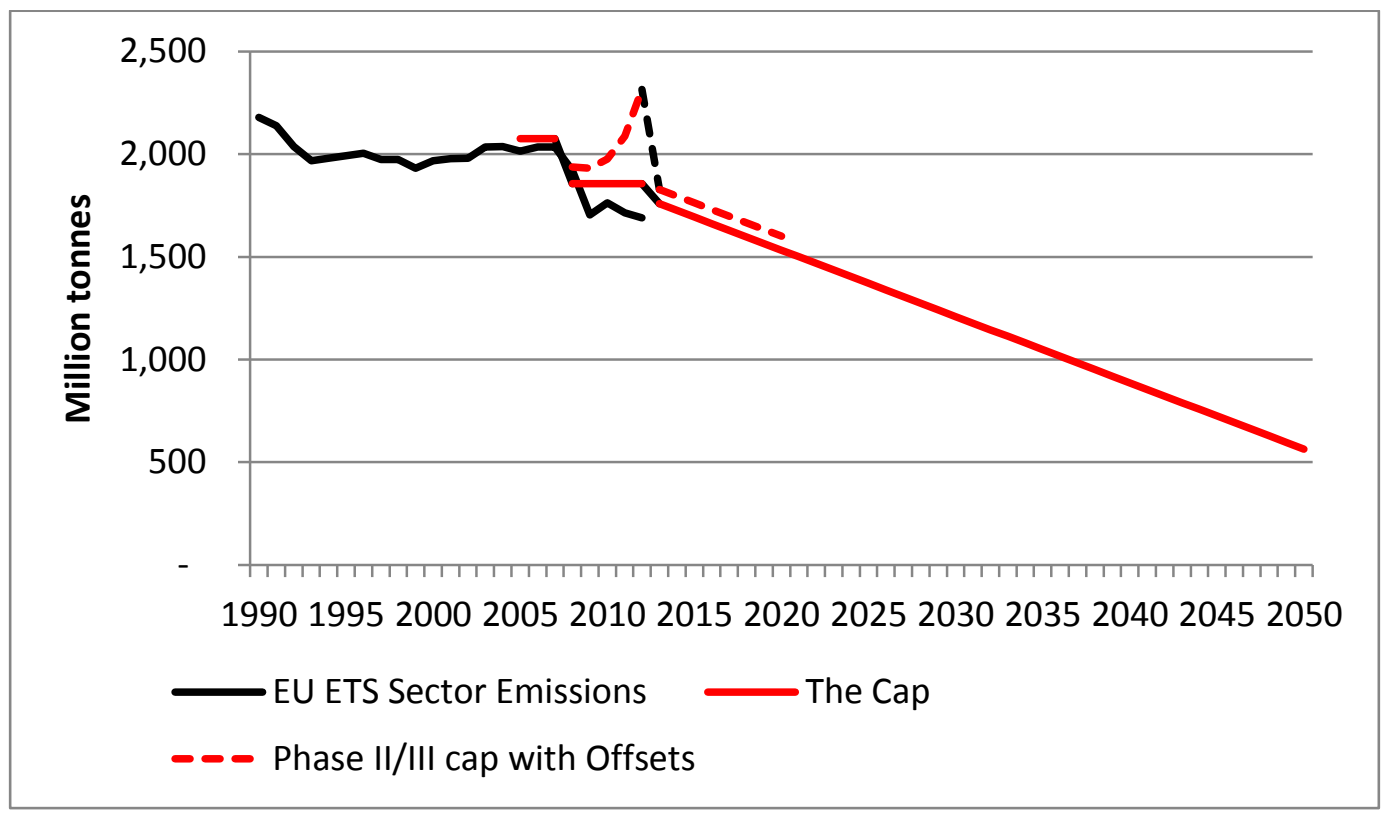

Source: Elaborated from Herold (2007), CITL/EUTL data-base, and OJEU (2013b).

In order to maintain comparability, the data shown in Figure 3 pertain only to the original EU25, that is, without Romania, Bulgaria and the EEA entrants, and without aviation, opt-ins, and the expansion of the ETS perimeter in 2013 to include additional sectors. The surge in the use of international credits in the last years of Phase II is readily evident as is the consequent limited amount of additional credits that may be used in Phase III (shown in Figure 3 as if used equally in the remaining years of Phase III). Emissions from this core, constituting $85 \%$ of the current EU ETS total continue to fall in line with the declining cap. A major issue is how the accumulated bank will be used over the coming years. Although large by any measure, if used over the next twenty years, the bank increases the post-2012 cap by less than 100 million tons annually through 2032on average.

\section{b. EUA prices}

Figure 4 shows the indices of the prompt-future prices for Phase I and Phase II+ allowances since early 2005. Futures contracts have become the main trading instruments in the EU ETS and the prompt future is the thickest of the futures contracts, which settle in early December shortly before the close of the compliance year and some five months before allowances must be surrendered against emissions. As can be readily seen, a visible uniform price for European Union Allowances (EUAs) has 
existed since the beginning of the EU ETS in 2005, thereby providing a single reference point by which abatement costs can be judged. What can be observed from Figure 4 is that the price has varied considerably over the eight plus years of the system's life. In particular, there was an interesting period in late 2006 and during 2007 when the law of one price did not seem to hold. In fact, it did since banking was not allowed between the 2005-08 "trial" period and the subsequent 2008-2012 trading period. Participants understood that there were two markets and that the degree of scarcity in the two would be different.

Figure 4: Prompt-future Prices for EUA in Phase I and Phase II \& III.

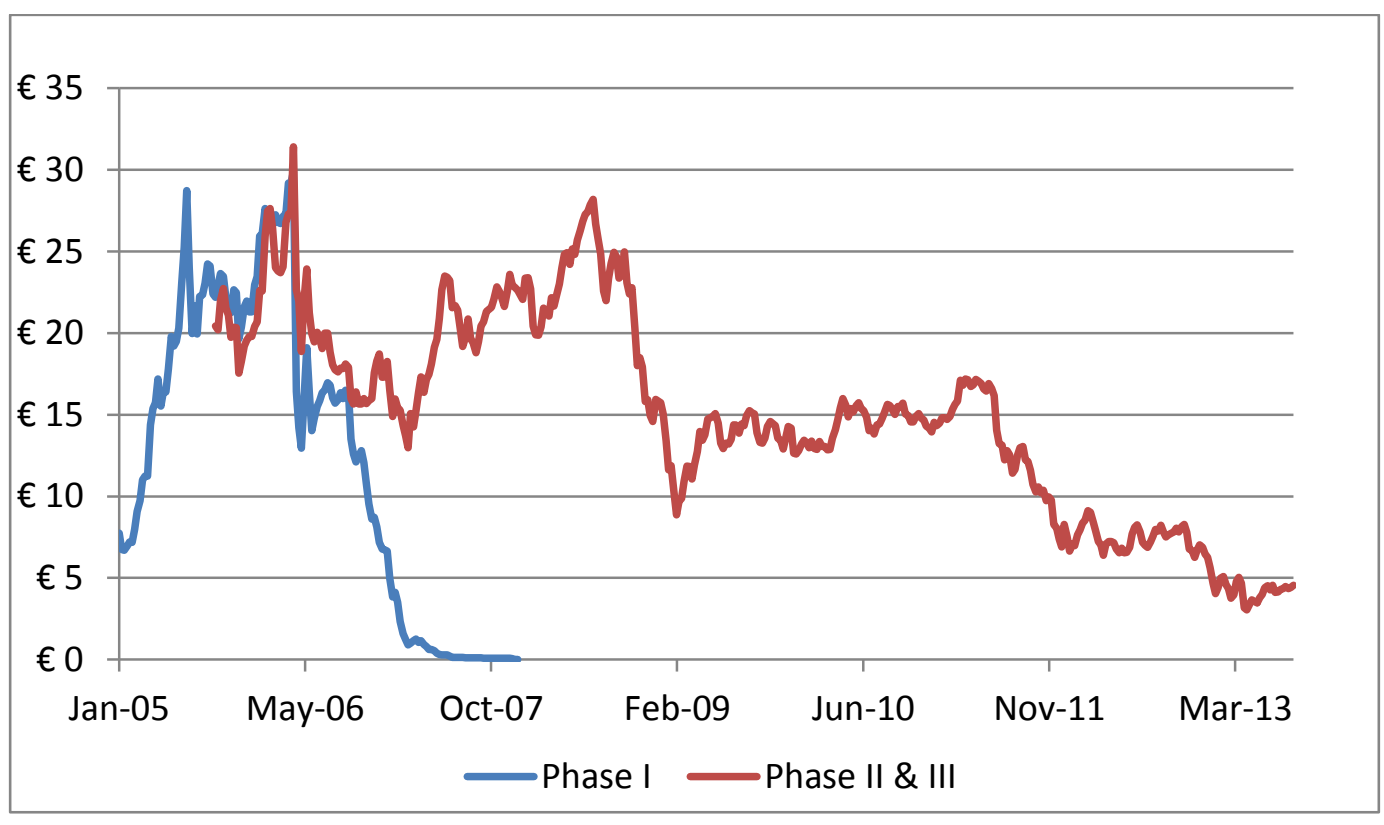

Source: Point Carbon.

Initially, the price of EUAs was expected to be between $€ 5-€ 10$ and the first quotes in early 2005 on the newly formed markets reflected this expectation. However, the EUA price rose quickly thereafter and led to a debate over the reasons for the unexpectedly high price, which lasted until late April 2006. At that time, several member states reported their emissions and all were lower than expected. As these reports came out in the space of one week in late April, the price for both Phase I and Phase II allowances fell significantly: the Phase I price by $50 \%$ and the Phase II price by about $30 \%$. The Phase I price held at around $€ 15$ during the summer of 2006, but as fall began and as it became increasingly clear that Phase I emissions would be below the cap, the price fell to a few euro-cents. Meanwhile, the Phase II price recovered to over $€ 20$ as Phase II began and reached almost $€ 30$ before the economic crisis of late 2008 reduced the EUA price again by about 50\%. This time, however, the price drop was not system-specific; many other asset values experienced similar declines. After some recovery in price in early 2009, the EUA price experienced a two-year period of remarkable stability with a price around $€ 15$ until the summer of 2011 when it fell again by around $50 \%$ to a new level of $€ 7-€ 8$ for 2012 before falling to a level around $€ 4$ with the start of Phase III. Despite prognostications that the price would fall to zero, so far it has stayed resolutely positive albeit at a low level with $€ 3.65$ being the lowest spot price observed.

The comparison between the price of EUAs at the end of Phases I and II and the size of the surplus allowances accumulated in each phase testifies to the importance of banking provisions. At the end of Phase I, the price went to zero and we know now after the reporting has been completed that the surplus was relatively small, 83 million allowances, roughly $4 \%$ of the annual limit. At the end of 2012, the accumulated surplus is 1.8 billion more than 20 times the size of the Phase I surplus and roughly equal to a year's emissions in Phase II, yet the price is not zero. The reason is that Phase II 
allowances can be banked for use in later years when the cap will be still lower, whereas the few surplus allowances in Phase I could not be used for what was also then a lower cap in Phase II.

As shown in Figure 5 below, two trends in the trading of EUAs in the marketplace are notable. First, the volume of trades involving EUAs has steadily increased over the life of the program. At the beginning, more than a year went by before trading exceeded 50 million tons a month. Over the next five years, trading volumes grew steadily to ten times that amount. The second notable trend is the shift in the location of trading. Initially, all trading was over-the-counter (OTC) as it has been for all other cap-and-trade programs. However, in 2005 organized exchanges started offering intermediary and hedging services and their share has grown steadily to account now for as much as $80 \%$ of the trades. While several exchanges offer these services, such as Nordpool in Norway, EEX in Germany, and the Green Exchange in the US, the most important has been the European Climate Exchange (ECX, now ICE) in London, which accounted for more than 90\% of the exchange volume in 2012. Most of the transactions on these exchanges are for futures. Spot transactions have constituted a small percentage of trades and the leading exchange for spot transactions, BlueNext in Paris, closed at the end of 2012.

Figure 5: EUA Monthly Volume

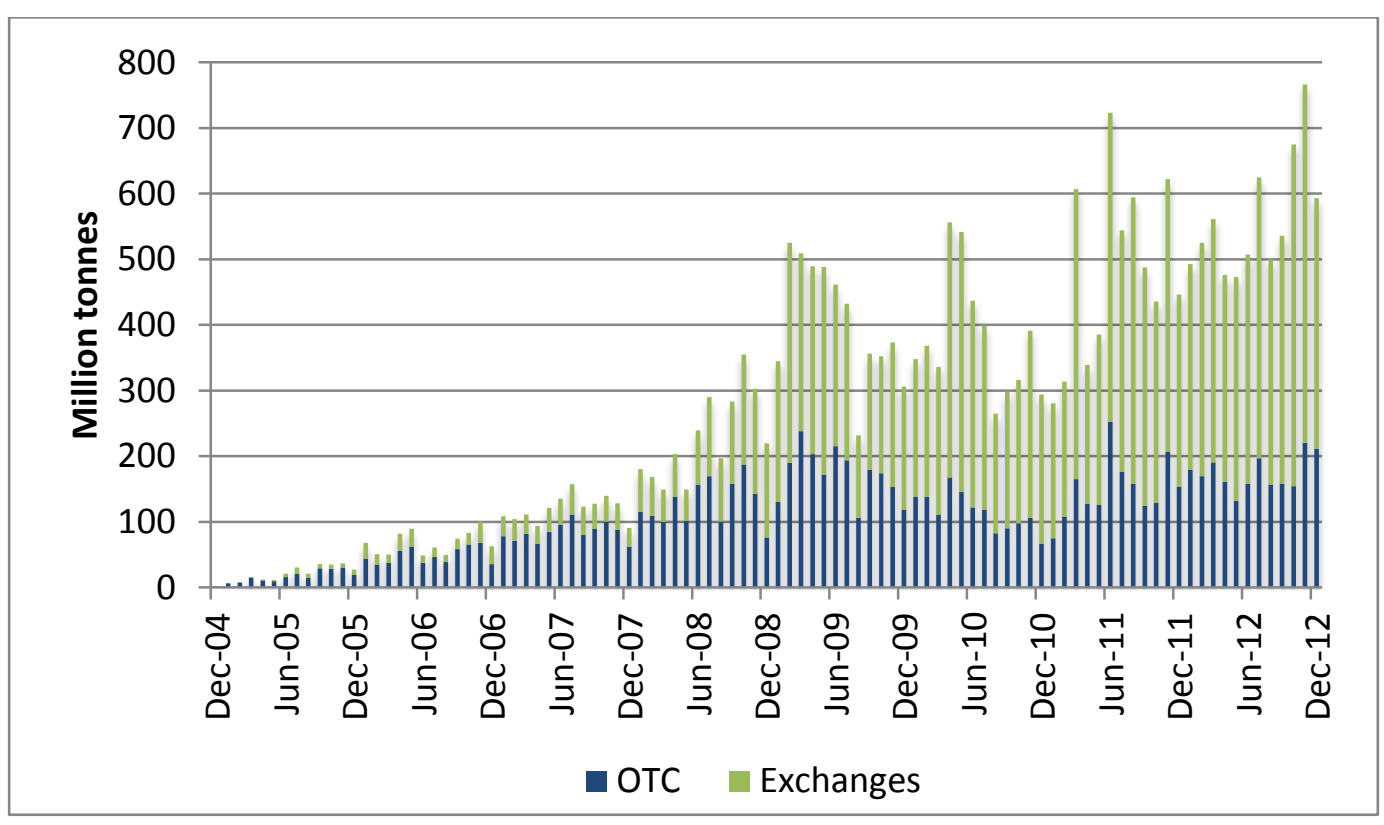

Source: Point Carbon.

An interesting feature of the EUA market is that as maturities lengthen futures prices are always increasing before the risk-free interest rate is taken into consideration, unlike similar pricing in commodity markets. Figure 6 shows the maturity profile of futures pricing at six points in time, early December from 2007 through 2012. To take the top line as an example, the start of the line shows the (imputed Phase II) spot price in December $2007^{6}$ and the remaining points on the line are the prices of the futures contracts maturing in December 2008 (the prompt future) through December 2012. Each successive line starts with the spot price of the following December and the futures prices then in existence. For all these lines (and for any of the thousand or so others that could be drawn reflecting different trading days), the price for the next maturity is always higher than the preceding one creating an almost constant relationship in which futures prices vary much the same as spot prices (or vice

6 There was no Phase II spot price in December 2007 since Phase II allowances were not distributed until February 2008. For the sake of consistency with the other lines, an imputed price is shown. It is calculated by applying the time yield between the Dec 2008 and Dec 2009 futures contracts as a discount to the observed Dec 2008 price. 
versa). The slope of the spread may change slightly and some small kinks can be observed, but overall the picture is one of remarkable stability: spot, near-future, and far-future prices move alike. Presumably, this constancy reflects the presence of banking, the lack of transportation costs, and the impossibility of a stock-out (since allowances do not have to be surrendered until four months after the close of the compliance year). As a result, tomorrow's expected price is today's plus some return for holding an allowance for the time until delivery. However, these returns vary significantly from the risk-free interest rate and remained an unresolved issue in EUA pricing.

Figure 6: EUA Pricing by Delivery Date at Selected Times

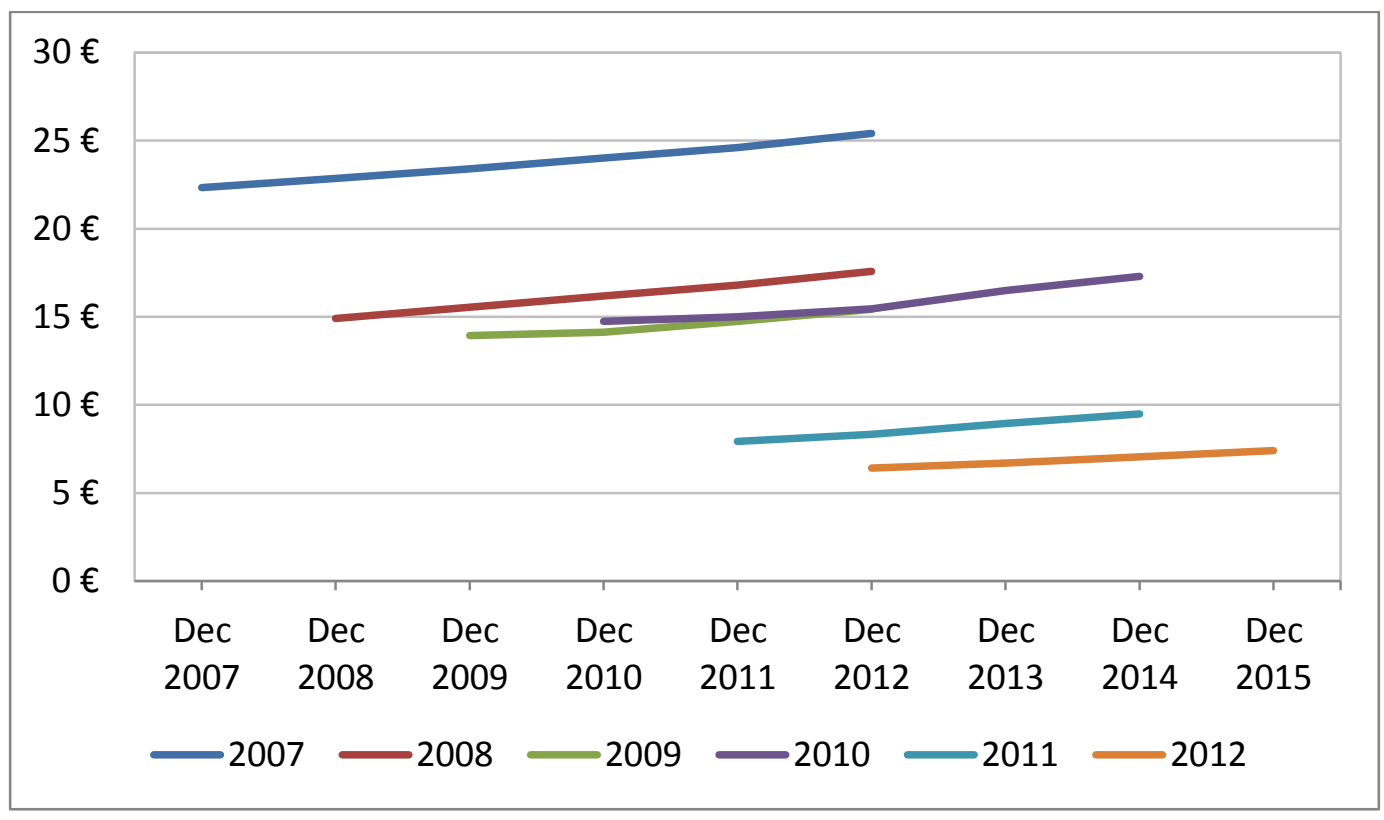

Source: Point Carbon.

Figure 7 illustrates the slight changes in the spread that do occur over time. In this case, the difference between the prompt-future contract and the next-near $(+1)$ contract is shown as a percentage of the prompt-future price. This provides a constant time period and uses the prices of the two futures with the greatest liquidity. With a few exceptions in Phase I, the interest rate is always positive and never higher than $10 \%$. For most of the EUA market's existence, the rate has fluctuated between $2 \%$ and $6 \%$. The same figure also shows the yield for the 1-year triple A European sovereign bonds. 
Figure 7: Time Yield for EUA Futures and the Euro Risk-free Rate

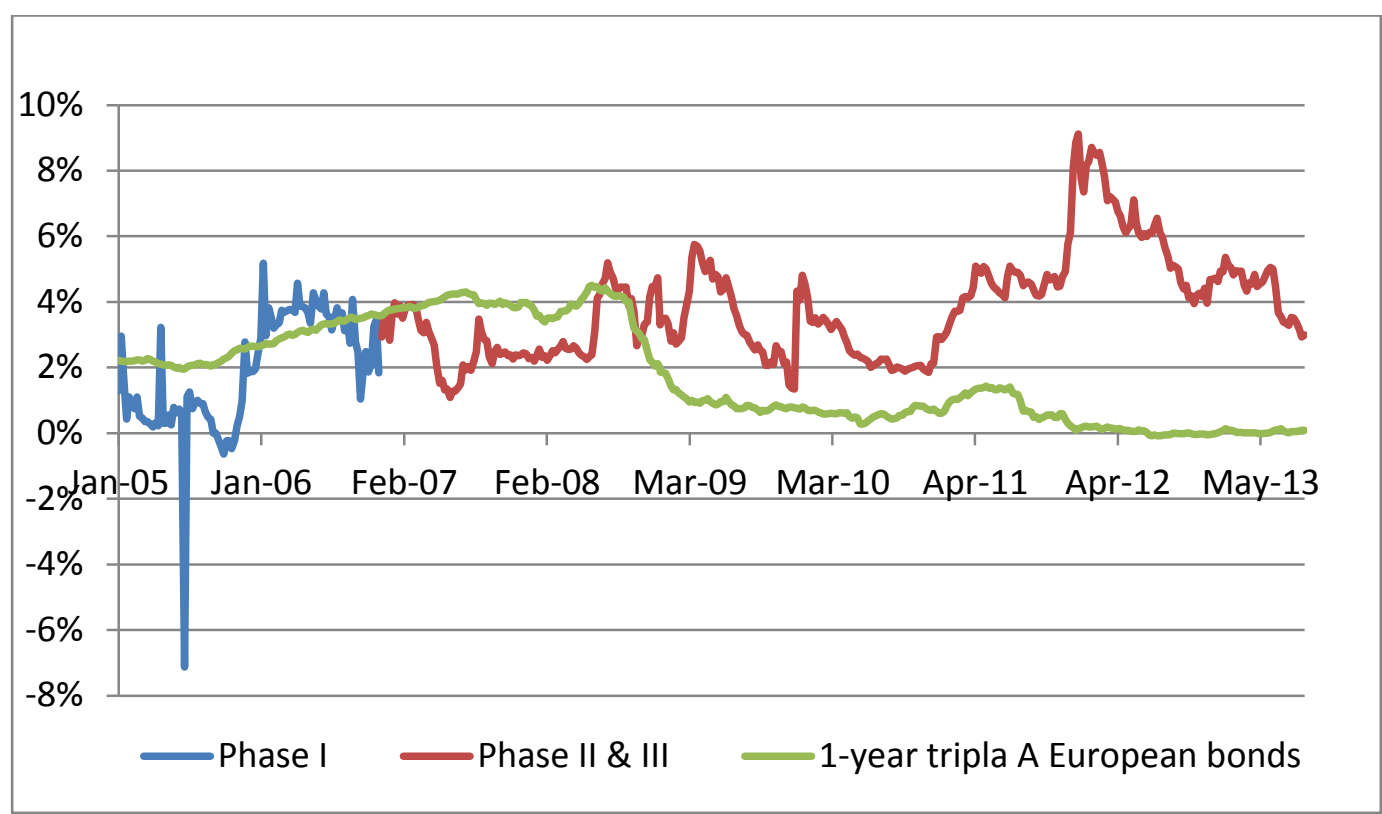

Source: Point Carbon, and European Central Bank.

\section{c. Offset use}

The EU ETS has conducted the boldest experiment to date in the use of offsets. Most cap-and-trade systems include provisions for offsets, but generally they are little used due mostly to the transaction costs involved in the implementation of monitoring, reporting and verification (MRV) procedures at off-system installations. The EU ETS broke new paths in two respects: it delegated MRV authority to a pre-existing outside entity, the Executive Board of the Clean Development Mechanism, and it allowed for significant potential offset use albeit with a limit and the use of a negative list to disallow certain types of projects. In the event, offsets were used for cover $11 \%$ of emissions, effectively $10.5 \%$ of the cap.

As shown by Figure 8, offset use started off very slowly at a level well below the limit of about $13 \%$ of annual allowed emissions (270 million annually) in the first two years, but use accelerated rapidly thereafter, especially for the credits created by the KPs JI procedures, known as Emission Reduction Units (ERUs), to the point that, in 2012, offsets provided the compliance instrument for one-fourth of emissions. Over all of Phase II, a total of 1.06 billion offsets were used, $11 \%$ of surrendered compliance instruments. Of this total, 676 million were CERs (credits from the Clean Development Mechanism known as Certified Emission Reductions) and 383 million ERUs. 
Figure 8: International Credit Use in the EU ETS by Year

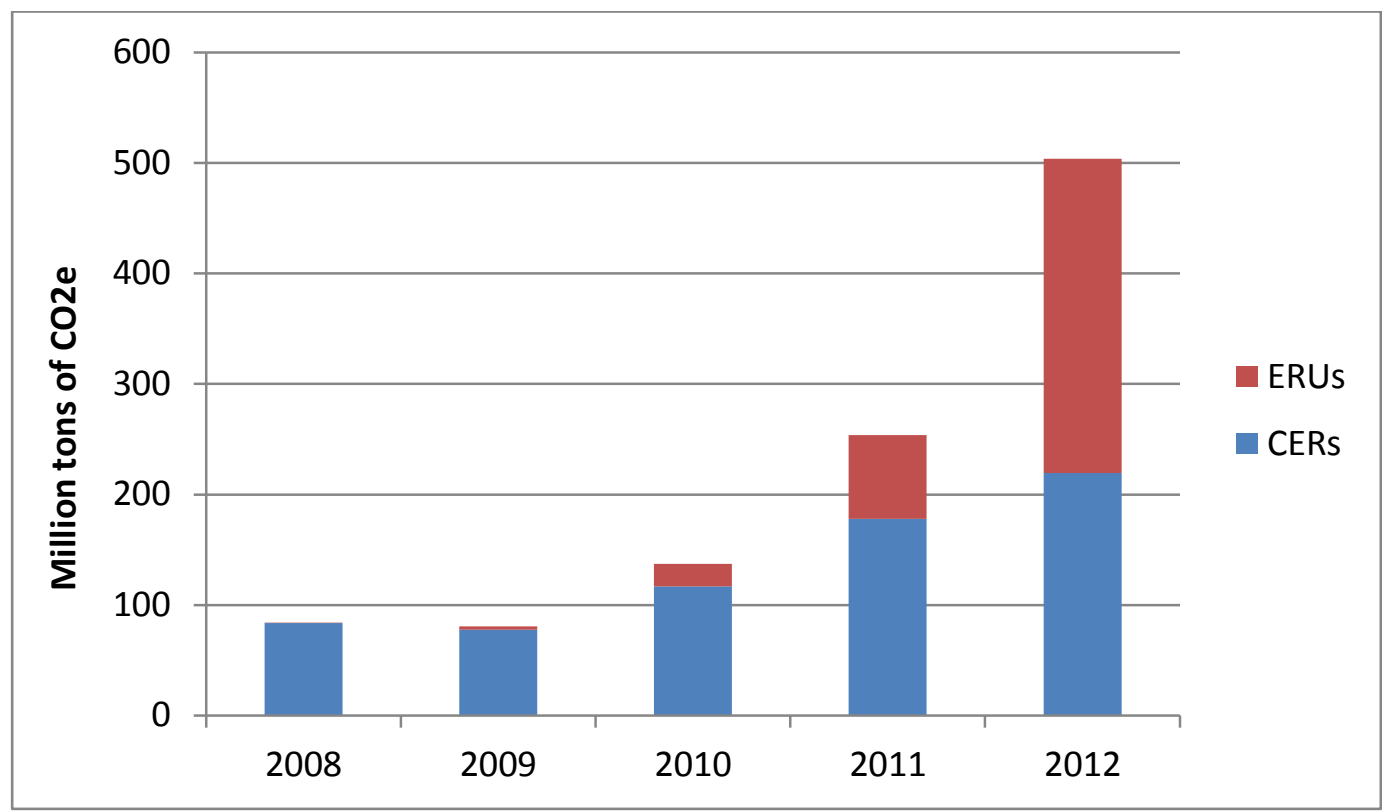

Source: CITL/EUTL data-base.

As shown in Figures 9, CERs and ERUs always sold at a discount to EUAs even though they are fully substitutable for EUAs within the limits established for installations in each member state's NAP. The CER discount varied greatly over Phase II beginning with a discount of 20-30\% that shrank to about $10 \%$ and then ended the period with a discount of more than $90 \%$ from an EUA price that was itself considered very low.

Figure 9: EUA and CER Pricing

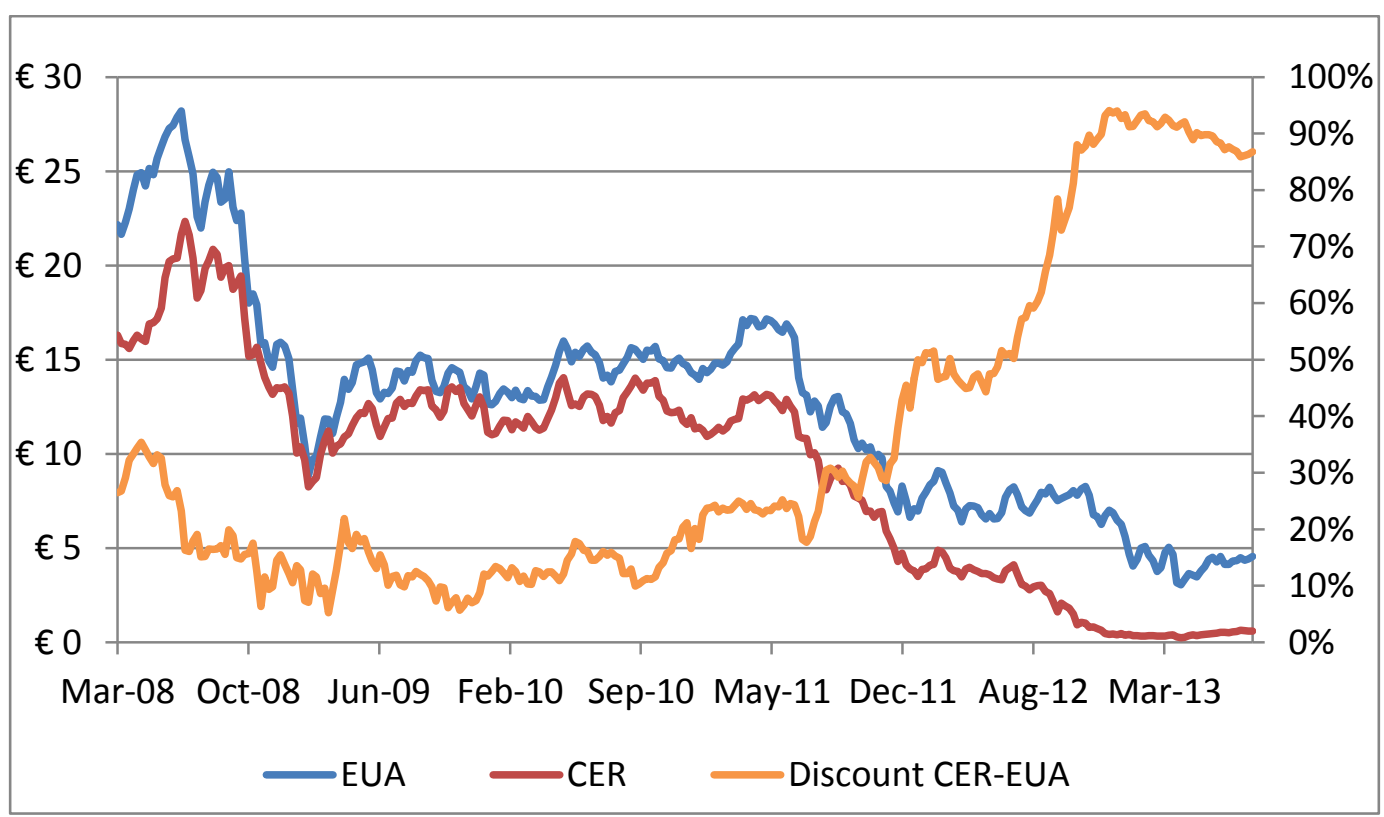

Source: Point Carbon.

Two factors largely explain the widening CER discount in the last two years of Phase II. The first is the announcement in June 2011 that credits from industrial gas projects, which account for nearly $60 \%$ of CERs issued, would not be allowed in Phase III (OJEU, 2011). The second is that the price in the 
alternative market for CERs and ERUs was collapsing even faster than the price of EUAs in the EU ETS as a result of the rapidly increasing supply (Fig 10 below) and reduced demand as the effects of the 2008 financial crisis on economic growth in Annex I countries became evident. In addition, those who were still buyers in the Kyoto market, such as Japan and Spain, turned increasingly to even cheaper surplus Kyoto allowances (AAUs) from Eastern Europe and the Former Soviet Union to meet their KP compliance needs. With the prospects of alternative, non-EU ETS demand steadily diminishing, the EU ETS became not just the preferred market, as it had always been, but increasingly the only market. This increasing resort on the EU ETS is seen in both the rapidly widening discount in 2011 and 2012, shown in Figure 9 above, and in the increasing share of total CER and ERU issuance being used in the EU ETS, as shown in Figure 10 below. Two inescapable consequences were a larger than expected bank of EUAs carried over into Phase III because of the surge of ERU issuance and use in 2011-12 and much less prospective credit use in Phase III since the 1.6 billion limit remained unchanged. These effects are illustrated graphically in Figure 3 above.

Figure 10: Cumulative Offset Issuance and ETS Surrenders

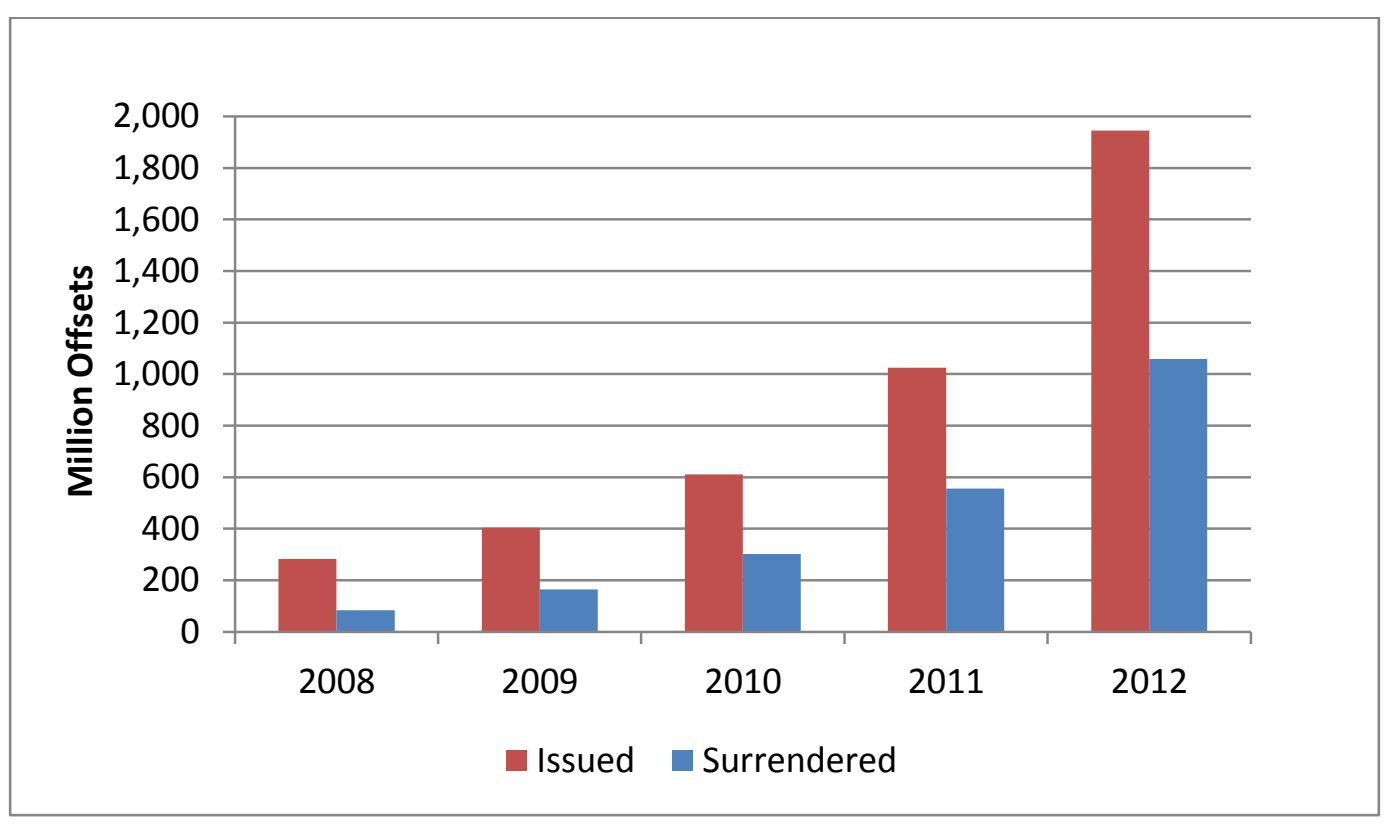

Source: UNEP Risø Centre and CITL/EUTL data-base.

The proportion of ETS surrenders to total issuance increased with each year going from $31 \%$ in 2008 to $56 \%$ in 2012. It should be noted that some of the CERs and ERUs issued may be on the EU ETS negative list and therefore not usable for compliance and a yet to be determined number will be used by Kyoto signatories to meet their Kyoto obligations. Also, the quantity issued as of March 2013, not to mention what may be issued subsequently, is larger than the 1.6 billion tons that are allowed for combined Phase II and Phase III use in the EU ETS.

Figures 11 and 12 present the composition of CERs and ERUs by project category and country of origin, respectively. 
Figure 11 Stock of Offsets Issued Through April 2013, by Project Category

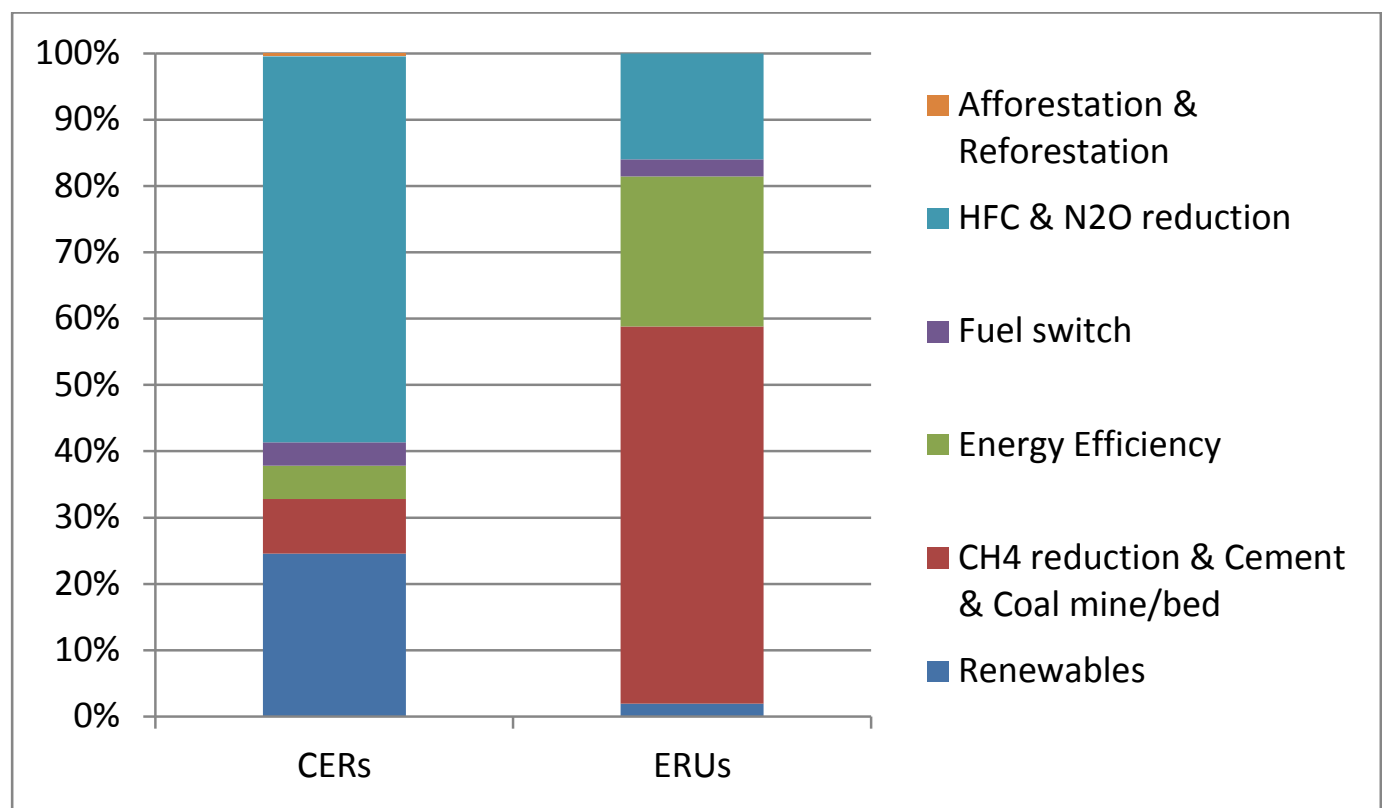

Source: UNEP Risø Centre.

The remarkable feature about the composition of these international credits by project category is that about two-thirds of all the credits issued are for non- $\mathrm{CO}_{2}$ greenhouse gas emissions, reflecting the high global warming potential assigned to these GHGs. Fifty-eight per cent of CERs issued so far come from industrial gas projects. The second largest share is represented by renewables projects at 25\%. This stands in marked contrast to the composition of the ERU stock at the end of the 2012 compliance year. Here $\mathrm{CH}_{4}$ (methane) reduction projects constitute 55\% of the total, with energy efficiency and industrial gas projects representing about $22 \%$ and $15 \%$, respectively. 
Figure 12: Stock of Offsets Issued Through April 2013, by Country of Origin

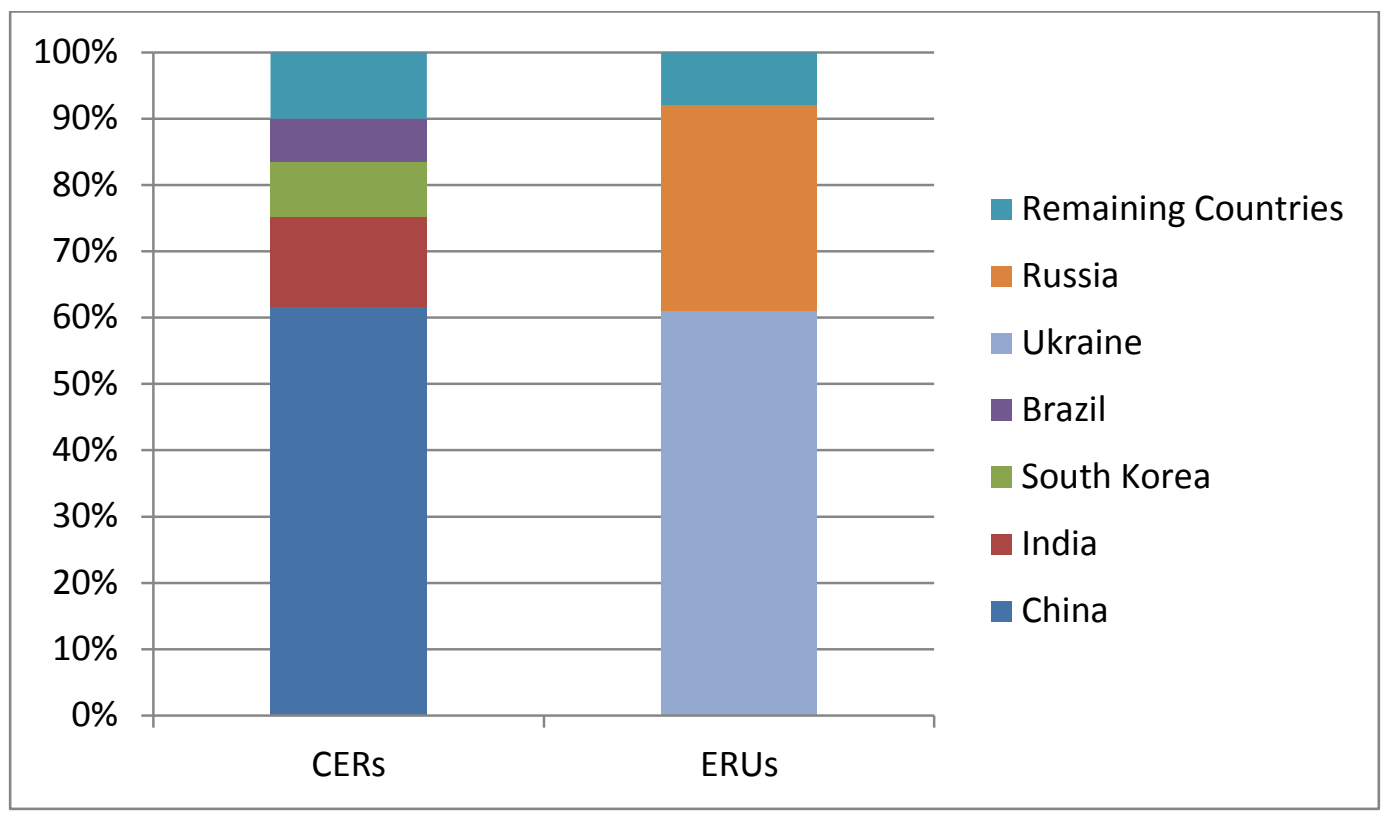

Source: UNEP Risø Centre.

As shown in Figure 12, the bulk of offsets originates in a small group of countries. China is the source of almost $62 \%$ of all CERs issued through the end of ETS Phase 2, with India, South Korea and Brazil combined accounting for another $28 \%$. The remaining $10 \%$ is spread over a larger number of countries. Concentration is even more extreme in the case of ERUs, where Ukraine accounts for $61 \%$ of total ERUs issued, with another $31 \%$ originating from Russia.

\section{Whither Phase III?}

The current debate about the ETS in Europe can be summarized as one between those who hold that the current price signals something fundamentally wrong with the ETS and those who argue that, in view of all that has happened in the interim, namely, reduced expectations for economic growth in the Eurozone and the significantly increased use of offsets in 2011-12, the current price indicates that the system is working exactly as it should. Fundamentally, this is a debate about objectives within climate policy: whether the objective is to reduce GHG emissions solely or in addition, or perhaps even principally, to transform the European energy system. No one suggests that emissions have exceeded the cap, or will do so; but the current prices do not seem likely to lead to a technological transformation that would greatly reduce reliance on fossil fuels.

Since mid-2012, this debate has focused on a proposal known as "back-loading," which would postpone auctioning of 900 million allowances from 2013-15 to 2019-20. The formal proposal would amend the ETS Directive to clarify that the Commission could adjust the timetable for auctioning allowances when appropriate "to ensure an orderly functioning of the market" (European Commission, 2012a). While some argue that withdrawing these allowances would boost prices in the near term, others counter that simply changing the timing of auctioning without changing the cumulative cap would have no effect on price.

Back-loading is, however, not just a debate over the timing of auctioned allowances in Phase III. It is a proxy battle over the bigger issue of whether to change the cap if not before 2020, then the trajectory thereafter in order to increase the carbon price and provide a stronger incentive for lowcarbon investment in Europe. Reducing the quantity of auctioned allowances now would provide time for a consensus to be built for tougher actions to be taken before the withdrawn allowances are re- 
injected back into the system in 2019-20. This could take the form of deciding to tighten the Phase III cap by the amount of the withdrawals, or to make an early change in the annual post-2020 decrement by an amount that would be judged sufficient to increase the price even with a reinjection of the withdrawn allowances. Accordingly, in November 2012, the Commission published a State of the Carbon Market report in which it laid out six alternatives for "restructuring" the EU ETS (European Commission, 2012b): increasing the EU reduction target to 30\% in 2020, retiring allowances in Phase III, early revision of the $1.74 \%$ annual linear reduction factor, extending the scope of the ETS to other sectors, limiting access to international credits, and creating a discretionary price management mechanism.

The back-loading and ETS restructuring debate feeds into and will inevitably become entangled with a closely related debate that is getting under way with the publication of a Green Paper on a 2030 framework for climate and energy policies (European Commission, 2013). The background for this debate is that there are no post-2020 targets for the renewable energy or energy efficiency components of the present $20-20-20$ by 2020 policy and the $1.74 \%$ annual linear reduction factor does not reduce GHG emissions to the level, 80\% below 1990 emissions, called for in the 2050 Roadmap (European Commission, 2011). The 2030 Green Paper raises questions not only about the restructuring of the ETS, but also concerning post-2020 targets for renewable energy and energy efficiency and the coordination of the latter targets with the ETS. In the normal course of things, the Commission would propose amendments to the relevant directives to create an appropriate 2030 framework for EU climate and energy policy. While consultations are ongoing, a formal proposal is not expected until after the expiration of the term of the current Parliament and Commission in 2014.

As this broader debate about climate and energy policy is engaged, one should not lose sight of what has been and is being achieved by the ETS. Absent a decision by the EU to abandon the program, which would require a super-majority, the ETS will march on with a continually declining cap that under all likely scenarios will create continuing scarcity thereby guaranteeing a carbon price as a permanent feature of the European economic landscape. The greatest political asset of the ETS is the force of inertia, as represented by the indefinitely continuing $1.74 \%$ annual linear reduction factor embedded in the Amended ETS Directive. If the consensus for concerted strong action that obtained in 2003 and 2008 breaks down, the ETS will be the only EU climate instrument in force after 2020. By the same token, it will not disappear or be repealed unless a super-majority of member states so votes. The only real threat to the ETS lies in continuing targeted mandates or subsidies, whether at the EU or member-state level, that would reduce emissions to the point where the declining cap is no longer binding. Cost and austerity argue against this eventuality, but it has happened elsewhere, notably in the US $\mathrm{SO}_{2}$ Emissions Trading Program, which remains a legal formality with an allowance price of less than $\$ 1 /$ ton of $\mathrm{SO}_{2}$.

\section{Conclusion}

The EU ETS remains a remarkable public policy achievement, and not least for being a multinational system. It has imposed a price on a significant share of the EU's $\mathrm{CO}_{2}$ emissions. Agents have responded in a manner that appears to have put emissions on a downward path that is clearly different from the evolution of economic activity, disappointing as that has been. The reduction is more than can be accounted for by other $\mathrm{CO}_{2}$-reducing climate and energy policies and has occurred notwithstanding significant use of offsets in Phase II. The evidence suggests that the price produced by the EU ETS has reduced emissions in Europe, although future research is needed to gain a better understanding of the approximate magnitudes.

During its now nine years of existence, the EU ETS has been subject of much controversy that has led to some remarkable changes in structure: greater centralization of functions, a progressive phaseout of free allocation of allowances in favor of auctioning, and sharply reduced use of offsets. With 2020 fast approaching and a price widely believed to be too low, the current debate is turning to 
mechanisms to regulate allowance supply, the coordination of the ETS with other EU climate policies, and the long-term ambition of the EU ETS. Through it all, the EU ETS will provide a valuable example, with many lessons, of what a multinational cap-and-trade system to regulate GHG emissions can and cannot do. 


\section{References}

Convery, Frank J. and Luke Redmond (2007), "Market and Price Developments in the European Union Emissions Trading Scheme," Review of Environmental Economics and Policy I.1:88-111 (winter 2007).

Ellerman, A. Denny and Barbara Buchner (2007), "The European Union Emissions Trading Scheme: Origins, Allocation, and Early Results," Review of Environmental Economics and Policy I.1:66-87 (winter 2007).

Ellerman, A. Denny, Barbara K. Buchner, and Carlo Carraro (2007), Allocation in the European Emissions Trading Scheme: Rights, Rents, and Fairness, Cambridge University Press.

Ellerman, A. Denny, Frank J. Convery, and Christian de Perthuis (2010), Pricing Carbon: The European Union Emissions Trading Scheme, Cambridge University Press.

European Commission (2000), Green Paper on Greenhouse Gas Emissions Trading within the European Union, COM(2000) 87 final, Brussels.

(2011), Communication from the Commission to the European Parliament, the Council, the European Economic and Social Committee and the Committee of the Regions: A Roadmap for moving to a competitive low carbon economy in 2050, COM(2011) 112 final, Brussels: 8.3.2011.

(2012a), Proposal for a Decision of the European Parliament and of the Council amending Directive 2003/87/EC clarifying provisions on the timing of auctions of greenhouse gas allowances, $\operatorname{COM(2012)~} 416$ final, Brussels: 25.7.2012.

(2012b), Report from the Commission to the European Parliament and the Council: The State of the European Carbon Market in 2012, COM(2012) 652 final, Brussels: 14.11.2012.

(2013), GREEN PAPER: A 2030 Framework for Climate and Energy Policies, COM(2013) 169 final, Brussels: 27.3.2013.

Herold, Anke. 2007. 'Comparison of verified $\mathrm{CO}_{2}$ emissions under the EU Emission Trading Scheme with national greenhouse gas inventories for the year 2005'. European Topic Centre on Air and Climate Change Technical Paper No 2007/3. Copenhagen: European Environment Agency (October).

Kruger, Joseph, Wallace E. Oates, and William A. Pizer (2007), "Decentralization in the EU Emissions Trading Scheme and Lessons for Global Policy," Review of Environmental Economics and Policy I.1:112-133 (winter 2007).

Official Journal of the European Union (OJEU, 2003), Directive 2003/87/EC of the European Parliament and of the Council of 13 October 2003 establishing a scheme for greenhouse gas emissions trading within the Community and amending Council Directive 96/61/EC, Brussels (25.10.2003): L 275/32-46.

(OJEU, 2004), Directive 2004/101/EC of the European Parliament and of the Council of 27 October2004 amending Directive 2003/87/EC establishing a scheme for greenhouse gas emission allowance trading within the Community, in respect of the Kyoto Protocol's project mechanisms, Brussels (13.11.2004): L 338/18-23.

(OJEU, 2009a), Directive 20008/101/EC of the European Parliament and of the Council of 19 November 2008 amending Directive 2003/87EC so as to include aviation activities in the scheme for greenhouse gas emission allowance trading within the Community, Official Journal of the European Union, Brussels (13.1.2009): L 8/3-21.

(OJEU, 2009b), Directive 2009/29/EC of the European Parliament and of the Council of 23 April 2009 amending Directive 2003/87/EC so as to improve and extend the greenhouse gas emission allowance trading scheme of the Community, Brussels (5.6.2009):L 140/63-87. 
(OJEU, 2011), Commission Regulation (EU) No 550/2011 of 7 June 2011 on determining, pursuant to Directive 2003/87/EU of the European Parliament and of the Council, certain restrictions applicable to the use of international credits from projects involving industrial gases, Brussels (8.6.2011): L 149/1-3.

(OJEU, 2013a), Decision No. 377/2013/EU of the European Parliament and of the Council of 24 April 2013 derogating temporarily from Directive 2003/87/EC establishing a scheme for greenhouse gas emission allowance trading within the Community, Brussels (15.4.2013): L 113/13.

(OJEU, 2013b), Commission Decision of 5 September 2013 concerning national implementation measures for the transitional free allocation of greenhouse gas emission allowances in accordance with Article 11(3) of Directive 2003/87/EC of the European Parliament and of the Council, Brussels (7.9.2013): L 240/27-35.

Skjaerseth, Jon Birger and Jorgen Wettestad (2008), EU Emissions Trading: Initiation, Decisionmaking and Implementation, Ashgate Publishing (http://www.ashgate.com)

Trotignon, Raphael and Anais Delbosc (2008), Allowance Trading Patterns during the EU ETS Trial Period: What Does the CITL Reveal?, Caisse des Depots Climate Report No. 13 (June) 


\section{Authors contacts:}

\section{A. Denny Ellerman; Claudio Marcantonini; Aleksandar Zaklan}

European University Institute

Robert Schuman Centre for Advanced Studies

Convento

Via delle Fontanelle 19

50014 San Domenico di Fiesole (FI)

Italy

Email: Denny.Ellerman@eui.eu; Claudio.Marcantonini@eui.eu; Aleksandar.Zaklan@eui.eu 